\title{
PENGARUH STORE ATMOSPHERE, DISPLAY PRODUCT, DAN PRICE DISCOUNT TERHADAP IMPULSE BUYING (Studi kasus pada Indomaret di kota Denpasar)
}

\author{
I Putu Widya Artana ${ }^{(1)}$ \\ I Gusti Bagus Satria Wisesa ${ }^{(2)}$ \\ I Komang Setiawan ${ }^{(3)}$ \\ Ni Luh Putu Mita Pramestya Utami ${ }^{(4)}$ \\ Ni Nyoman Kerti Yasa ${ }^{(5)}$ \\ Made Jatra $^{(6)}$
}
(1)(2)(3)(4)(5)(6) Program Studi Manajemen Fakultas Ekonomi dan Bisnis, Universitas Udayana, Bali, Indonesia e-mail: putuwidyaartana@gmail.com

\begin{abstract}
ABSTRAK
Studi ini bertujuan untuk menjelaskan pengaruh Store Atmosphere, product display, dan Price Discount terhadap Impulse Buying. Sampel yang digunakan sebanyak 90 responden menggunakan teknik purposive sampling yaitu bertempat tinggal di Kota Denpasar, dan pernah melakukan Impulse Buying. Data dianalisis menggunakan analisis regresi. Hasil penelitian ini menunjukkan bahwa Store Atmosphere berpengaruh positive dan signifikan terhadap Impulse Buying; product display berpengaruh positive signifikan terhadap Impulse Buying; dan Price Discount berpengaruh positive signifikan terhadap Impulse Buying. Implikasi penelitan ini memberikan saran kepada pihak indomaret agar selalu mengembangkan store atmoshere dan product display menjadi lebih baik, serta tetap memberikkan kebijakan Price Discount.
\end{abstract}

Kata kunci : Store Atmosphere, Display Product, Price Discount, Impulse Buying.

\begin{abstract}
This study aims to explain the effect of Store Atmosphere, product display, and Price Discount on Impulse Buying. The sample used was 90 respondents using purposive sampling technique that resided in Denpasar City, and had carried out Impulse Buying. Data were analyzed using regression analysis. The results of this study indicate that Store Atmosphere has a positive and significant effect on Impulse Buying; product display has a significant positive effect on Impulse Buying; and Price Discount has a significant positive effect on Impulse Buying. The implications of this research suggest that Indomaret always develop store atmoshere and product displays to be better, and still provide a Price Discount policy.
\end{abstract}

Keywords: Store Atmosphere, Display Product, Price Discount, Impulse Buying. 
Putu Widya Artana, I Gusti Bagus Satria Wisesa, I Komang Setiawan, Ni Luh Putu Mita Pramestya Utami, Ni Nyoman Kerti Yasa, dan Made Jatra. Pengaruh Store Atmosphere, Display Product, dan Price Discount...

\section{PENDAHULUAN}

Usaha ritel di Indonesia dari tahun ke tahun mengalami pertumbuhan yang sangat pesat. Pertumbuhan inilah yang menyebabkan persaingan dalam usaha ritel menjadi sangat ketat. Pertumbuhan yang terjadi diikuti dengan meningkatnya daya beli masyarakat. Hal inilah yang mendorong pelaku bisnis untuk bias lebih proaktif dan berinovasi dalam memberikan produk maupun pelayanan yang prima untuk mendapatkan keunggulan bersaing untuk memenangkan pangsa pasar.

Pesatnya perkembangan ritel modern ini, berdasarkan pada keinginan perusahaan untuk memenuhi kebutuhan pelanggannya (Sari dan Ikhwan Faizal 2018). Perkembangan bisnis ritel juga disebabkan oleh semakin banyaknya konsumen yang ingin berbelanja dengan mudah dan nyaman ( Arvinia dkk, 2013). Bisnis ritel merupakan semua kegiatan penjualan barang dan jasa secara langsung pada konsumen akhir untuk pemakaian pribadi dan rumah tangga, bukan untuk keperluan bisnis ( Tjiptono, 2016 : 258 ).

Bisnis ritel di Indonesia cukup menarik bagi pendatang baru dimana pasar yang ada saat ini cukup potensial melihat peningkatan perekonomian dan peningkan jumlah penduduk Negara (Euis, 2008). Pesatnya perkembangan yang terjadi mengakibatkan adanya persaingan diantara pengusaha ritel. Salah satu bentuk dari usaha ritel minimarket. Menurut Ma`aruf (2005:84) minimarket adalah gerai ritel dengan konsep modern yang menjual kebutuhan sehari-hari yang lokasinya berada di sekitar wilayah pemukiman penduduk sehingga mudah dijangkau dan dapat menyaingi gerai-gerai atau warung-warung ritel yang masih bersifat tradisional. Salah satu usaha minimarket yang berkembang di Indonesia 
adalah Indomart. Indomart adalah salah satu jaringan minimarket terbesar Indonesia yang menawarkan sejumlah barang kebutuhan sehari-hari.

Indomaret adalah jaringan minimarket yang gerainya sudah banyak tersebar di hampir seluruh penjuru Indonesia. Berdasarkan data indomaret.co.id, jumlah gerai indomaret hingga tahun 2019 ini lebih dari 16.000 gerai yang tersebar di seluruh penjuru Indonesia. Dari sekain banyak gerai indomaret, 24 diantaranya berada di wilayah kota Denpasar (tiendeo.co.id). Meskipun mempunyai jumlah gerai yang banyak, indomaret masih harus terus bersaing dengan gerai-gerai minimarket yang lain.

Dengan bertambahnya jumlah industi ritel, maka pemasar harus memahami kebutuhan dan keinginan kosumen, serta membuat strategi-strategi yang dapat mempertahankan pelanggan dan menarik pelanggan baru. Amiri et al. (2012), menyatakan seiring dengan kebutuhan konsumen yang semakin bervariasi dan penting bagi pelaku bisnis terutama dalam industri ritel untuk merespon hal tersebut. Hal ini dikarenakan daya beli masyarakat yang mengalam perubahan. Para peritel melihat peluang ini untuk meningkatan omzet penjualan tiap tahun melalui kegiatan belanja yang dilakukan oleh konsumen ndomaret.

Salah satu cara yang dapat dilakukan oleh indomaret dalam melakukan persaingan dalam indistri ritel adalah dengan cara memperbesar Impulse Buying yang dilakukan oleh konsumen. Menurut Kurniawan dan Yohanes (2013), Impulse Buying dapat diartikan sebagai tindakana pembelian yang dilakukan secara mendadak dan tanpa melalui proses perencanaan sebelumnya. Pembelian impulsive telah dianggap sebagai fenomena yang khas dan meresap dalam gaya 
Putu Widya Artana, I Gusti Bagus Satria Wisesa, I Komang Setiawan, Ni Luh Putu Mita Pramestya Utami, Ni Nyoman Kerti Yasa, dan Made Jatra. Pengaruh Store Atmosphere, Display Product, dan Price Discount...

hidup seseorang dan teruss mengalami peningkatan (Ahad et al., 2015 ). Impulse Buying terjadi ketika seseorang belum mencari produk tertentu dan belum memiliki niat untuk membeli (Khorrami et al., 2015).

Adanya pembelian impulif ini merupakan pengaruh positif bagi peritel guna meningkatkan omzet penjualan perusahaan. Pemahaman mengenai perilaku Impulse Buying dapat memberikan pedoman bagi peritel dalam mengembangkan strategi yang menambah peluang dalam berbelanja. Hal ini menguatkan bahwa Impulse Buying yang dilakukan oleh konsumen atau pelanggan sangat berkontribusi dalam meningkatkan omzet penjualan yang didapat oleh peritel tersebut.

Impulse Buying merupakan jenis pembelian yang mendominasi pasar ritel hingga saat ini. Proporsi Impulse Buying dalam binsis ritel mencapai 80 persen (Choudhary, 2014). Berdasarkan survey yang dilakukan oleh Bayley et al. (2007) menyebutkan bahwa 50 persen dari 65 persen pembelian uang dilakukan pada gerai ritel merupakan jenis pembelian yang tidak direncanakan atau Impulse Buying.

Christina (2010 : 69 ) menjelaskan bahwa salah satu penyebab terjadinya pembelian impulsif adalah pengaruh stimulus dari tempat belanja tersebut, dan menurut Maymand \& Mostafa (2011) lingkungan stimulasi termasuk dalam rangsangan eksternal dimana rangsangan eksternal pembelian impulse mengacu pada rangsangan pemasangan yang dikontrol dan dilakukan oleh pemasar, yang mana dapat melalui kegiatan penciptaan atmosfer toko, potongan harga dan Display Product pada gerai itu sendiri. 
Atmosfer toko perlu diperhatikan oleh pemasar ritel khususnya minimarkate karena pengaturan atmosfer toko yang baik akan membuat konsumen merasa nyaman dan betah berlama-lama berada dalam toko sehingga dapat meninkatkan potensi konsumen untuk berbelanja lebih banyak (Hussain, 2015). Konsumen yang berada di dalam gerai dalam waktu yang lama akan dapat meningkatkan potensi pembelian tidak terencana yang dilakukannya (Setiawati dan Sukawati, 2017). Dewi dan Giantari (2015) menyatakan bahwa atmosfer toko sangat perlu diperhatijan oleh pemasar karena dengan pengaturan atmosfer yang baik dapat menyentuh emosi konsumen untuk berbelanja lebih banyak.

Pengaruh dari atmosfer toko terhadap Impulse Buying ini telah dibuktikan oleh beberapa peneltian yang telah dilakukan. Berdasarkan penelitian yang dilakukan oleh Pemayun dan Ekawati (2016), Darmayasa dan Sukaatmadja (2017), Dharma dan Kusumadewi (2018) memperlihatkan bahwa atmosfer toko mempunyai pengaruh yang positif signifikan terhadap Impulse Buying yang mana penelitian ini memperoleh hasil yang sama dengan penelitian yang dilakukan oleh Dewi dan Giantari (2015), Temaja dkk (2015) yang juga menyatakan bahwa atmosfer toko berpengaruh positif signifikan terhadap Impulse Buying

Faktor lain yang dapat mempengaruhi Impulse Buying dalam gerai ritel adalah penataan atau display dari produk yang dijual. Menurut Sarma (2014), penataan produk merupakan sebuah alat pemasaran yang perlu diperhatikan karena bagian dari POP stimuli atau Point of Purchese Stimuli yang dapat mendorong konsumen untuk melakukan pembelian implusif. Penataan produk memang salah satu hal yang penting dalam gerai ritel yang mana penataan produk 
Putu Widya Artana, I Gusti Bagus Satria Wisesa, I Komang Setiawan, Ni Luh Putu Mita Pramestya Utami, Ni Nyoman Kerti Yasa, dan Made Jatra. Pengaruh Store Atmosphere, Display Product, dan Price Discount...

yang baik dan menarik dapat membuat orang-orang merasa tertarik dan menimbulkan rasa ingin berbelanja.

Pengaruh penataan produk terhadap Impulse Buying ini juga didukung oleh penelitian yang dilakukan oleh Muthiah dkk (2018) yang menyatakan bahwa penataan produk dapat berpengaruh secara positif signifikan terhadpa Impulse Buying. Penelitian-penelitian tersebut juga didukung oleh penelitian lainnya seperti penelitian yang dilakukan oleh Winawan dan Yasa (2014), yang juga menyatakan bahwa penataan produk berpengaruh positif signifikan terhadap impukse buying.

Price Discount adalah salah satu strategi promosi penjualan dengan menawarkan produk dengan harga yang lebih rendah dari seharusnya (Gumilang dan Nurcahya, 2016). Menurut Chen et al. (2012) menyatalan bahwa Price Discount atau potongan harga merupakan strategi pemasaran yang penggunaan paling banyak baik itu secara online maupun secara offline. Dengan penawaran produk dengan harga yang lebih rendah daripada seharusnya maka akan dapat menarik minat konsumen agar dapat berbelanja lebih banyak.

Pengaruh Price Discount terhadap Impulse Buying ini sudah dibuktikan dengan hasil dari beberapa penelitian seperti penelitian yang dilakukan oleh Gumilang dan Nurcahya (2016), Melina dan Khadafi (2017) yang menyatakan bahwa Price Discount mempunyai pengaruh positif dan signifikan terhadap Impulse Buying. penelitian ini juga didukung oleh penelitian yang dilakukan oleh Setyaningrum dkk. (2016), Suhiryanto dkk. (2018) yang juga menyatakan bahwa Price Discount mempunyai pengaruh positif signifikan terhadap Impulse Buying. 
Berdasrkan latar belakang yang ada maka penelitian ini memiliki tujuan untuk mengetahui pengaruh Store Atmosphere, Price Discount, dan Display Product terhadap Impulse Buying.

\section{KAJIAN PUSTAKA DAN HIPOTESIS}

\section{Store Atmosphere}

Menurut Rahmadana (2016), Store Atmosphere merupakan lingkungan gerai atau toko yang didesain sedemikian rupa melalui pencahayaan, musik, warna, penciuman, dan komunikasi visual yang dapat digunakan untuk mendorong perilaku berbelanja seseorang. Semakin menarik pengaturan suasana toko atau gerai maka akan membuat konsumen (Dharmayasa dan Sukaatmadja, 2017). Berdasarkan hal tersebut, dapat dikatan bahwa pengaturan suasana toko yang baik dapat memperbesar peluang pembelian tidak terencana tersebut.

Menurut Ma`aruf (2006), suasana toko yang baik bisa disebabkan oleh indicator-indokator sebagai berikut: 1) Perencanaan Toko: Perencanaan toko yang dimaksud adalah ketersediaan ruang dan tata letak yang ada di dalam gerai yang mana tata letak mengarah pada ketersediaan jalan atau tempat konsumen berlalulalang di dalam toko itu sendiri. Semakin mudah konsumen bergerak di dalam toko maka akan membuat konsumen merasa nyaman berada di dalam toko. 2) Komunikasi Visual: Komunikasi visual adalah bagaimana perusahaan ritel berusaha melakukan komunikasi dengan konsumen dengan menggunakan wujud tertentu yang dapat mewakili perusahaan itu sendiri, seperti lambing, iklan, suara 
Putu Widya Artana, I Gusti Bagus Satria Wisesa, I Komang Setiawan, Ni Luh Putu Mita Pramestya Utami, Ni Nyoman Kerti Yasa, dan Made Jatra. Pengaruh Store Atmosphere, Display Product, dan Price Discount...

dll. 3) Desain Toko: Desain toko adalah proses untuk menciptakan atau menghadirkan obejk-objek baru di dalam toko itu sendiri yang mana dalam desain toko ini memperhatikan aspek estetika, fungsi dan lain sebagainya, seperti pengayuran pada pencahayaan, kebersihan, suhu ruangan dan lain sebagainya.

\section{Display Product}

Display Product atau penataan produk adalah sebuah hal penting yang dilakukan dalam gerai atau toko ritel karena, penataan produk yang baik dapat meningkatkan minat pembeli dalam berbelanja. Menurut Rahmadana (2016), pemasar harus dapat menata produk yang ditawarkan dengan baik karena hal tersebut dapat membuat konsumen akan merasa nyaman danbetah berada di dalam toko untuk berbelanja. Penataan produk yang baik akan membuat daya tari dari penglihatan bagi konsumen sehingga memberikan kesan yang positif bagi konsumen (Alma. 2014:189).

Menurut Rahmadana (2016), untuk mendapatkan Display Product yang baik harus memperhatikan indicator-indikator sebagai berikut: 1) Interior Display: Interior Display dapat diartikan sebagai pengaturan tampilan atau tata letak produk, gambar, harga dan lain sebagainya yang berkaitan dengan produk yang berada di dalam toko itu sendiri. Dengan tata letak yang rapi dan berurutan sesuai jenis produk, konsumen akan merasa nyaman dan dimudahkan dalam mencari produk yang ingin dibelinya. 2) Eksterior display: Eksterior display dapat diartikan sebagai pengaturan tampilan atau tata letak produk, poster, dan symbol di Kawasan luar toko yang menyasar calon konsumen yang berada di luar toko, sehingga berkenan untuk membeli produk yang ditawarkan tersebut. Eksterior 
display dapat menarik konsumen terutama yang berada di luar toko yang sedang melintas di sekitar area toko. 3) Window Display: Window Display dapat diartikan sebagai pengaturan tampilan atau tata letak produk, gambar, poster, symbol dna lain sebagainya yang berkaitan dengan produk dari dalam toko dengan menyasar calon konsumen yang berada di luar toko. Window display yang baik dapat membuat calon konsumen di luar toko yang melihatnya akan merasa tertarik membeli produk tersebut.

\section{Price Discount}

Price Discount atau potongan harga adalah salah satu strategi pemasaran yang banyak digunakan yang mana dalam hal ini pemasar mencoba menawarkan produk dengan harga lebih rendah daripada harga seharusnya dengan harapan konsumen akan merasa tertarik sebuah produk. Menurut Tjiptono (2008: 229), potongan harga merupakan pemotongan harga suatu produk dari harga normalnya pada periode tertentu, sementara itu menurut Kotler (2005: 303) menyatakan potongan harga adalah kebijakan pemotongan harga terhadap produk dalam periode tertentu untuk meningkatkan penjualan. Pemotongan harga ini sering digunakan pemasar sebagai salah satu strategi pemasaran baik secara online maupun offline.

Menurut Wahyudi (2017), indikator dari Price Discount antara lain: 1) Frekuensi Diskon: Frekuensi diskon mengacu pada seberapa sering pemasar dalam suatu gerai ritel melakukan potongan harga terhadap produk yang ditawarkannya. 2) Besaran Diskon: Besaran diskon merupakan seberapa besar diskon yang ditawarkan oleh pemasar terhadap produk yang ditawarkan kepada 
Putu Widya Artana, I Gusti Bagus Satria Wisesa, I Komang Setiawan, Ni Luh Putu Mita Pramestya Utami, Ni Nyoman Kerti Yasa, dan Made Jatra. Pengaruh Store Atmosphere, Display Product, dan Price Discount...

konsumennya, yang dapat dilihat dari presentase misalnya 30\%, 50\% dll.3) Waktu Pemberian Diskon: Waktu pemberian diskon merujuk pada kapan saja waktu yang dipilih pemasar untuk melakukan potongan harga produk yang ditawarkan kepada para konsumen.

\section{Impulse Buying}

Impulse Buying adalah sebuah tindakan pembelian produk yang tidak direncanakan sebelumnya yang terjadi sebagai dari akibat rangsangan yang diterima dan tindakan ini langsung diputuskan saat itu juga (Kacen dan Lee, 2002). Pembelian tidak terencana adalah tindakan pembelian yang dilakukan oleh konsumen yang berbeda dari apa yang telah direncanakan sebelumnya yang mana perilaku ini sering muncul karena disebakan oleh berbagai rangsangan yang dilakukan oleh pemasar pada suatu toko atau gerai ritek tempat konsumen tersebut berada (Pontoh dkk, 2017).

Menurut Kacen dan Lee (2002), indikator yang dapat digunakan untuk mengetahui pembelian tidak terencana ini adalah sebagai berikut: 1) Pertimbangan yang dilakukan dalam pembelian ini tidak panjang. 2) Pembelian tidak terencana dapat terjadi karena disebabakan oleh rangsangan dari produk, warna, label dll. 3) Pembeli tidak mempunyai rencana sebelumnya untuk melakukan pembelian terhadap sebuah produk. 


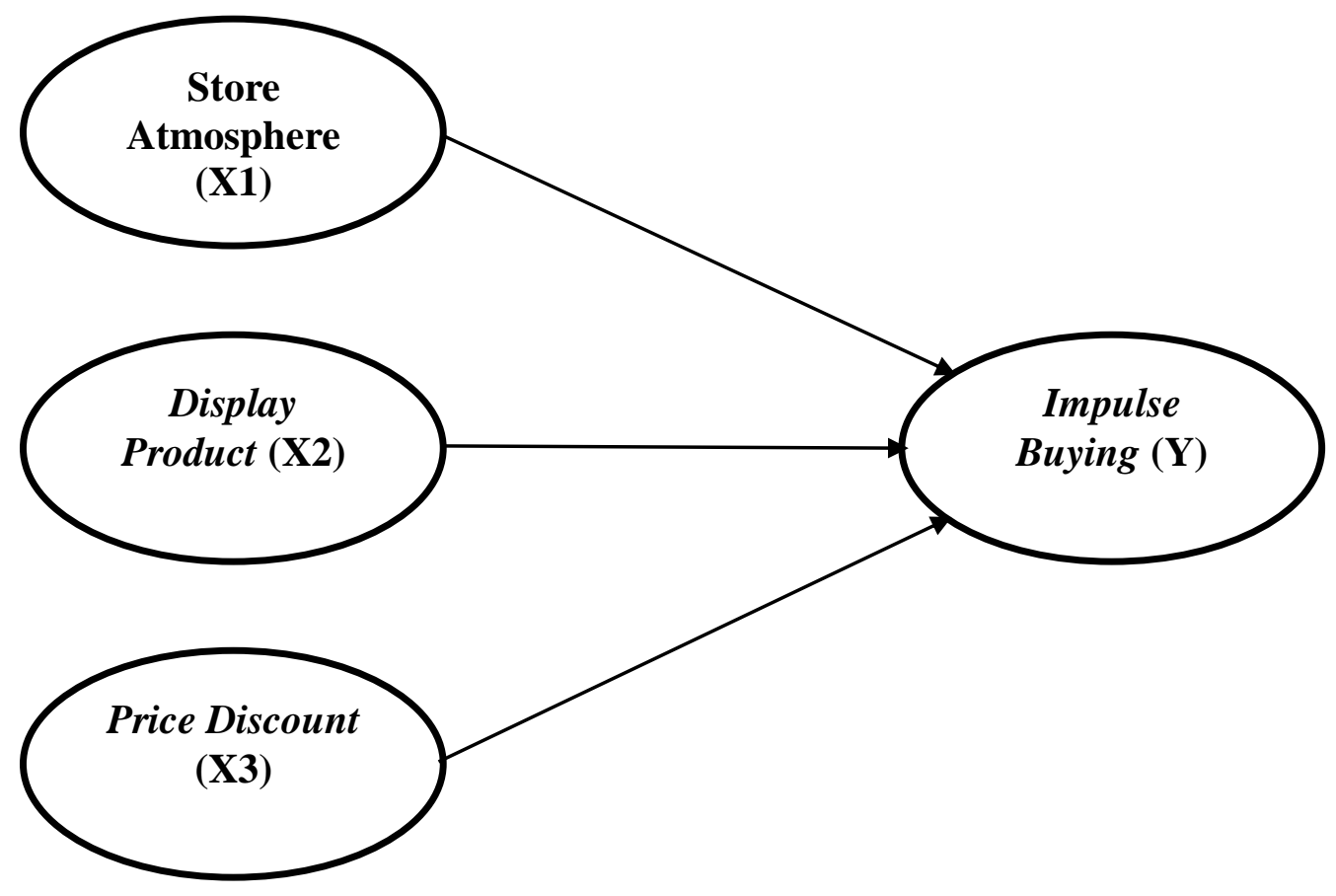

Gambar 2.1 Kerangka Konseptual

\section{Hipotesis Penelitian}

Pengaruh Store Atmosphere terhadap Impulse Buying.

Penelitian yang dilakukan oleh Pemayun dan Ekawati (2016), Dharma dan Kusumadewi (2018) menyatakan bahwa bahwa atmosfer toko berpengaruh yang positif signifikan terhadap Impulse Buying. Pada penelitian yang dilakukan oleh Dewi dan Giantari (2015) yang juga menyatakan bahwa atmosfer toko berpengaruh positif signifikan terhadap Impulse Buying.

Berdasarkan hasil penelitian sebelumnya, maka hipotesis dalam penelitian ini adalah sebagai berikut:

H1: Store Atmosphere mempunyai pengaruh positif dan signifikan terhadap Impulse Buying. 
Putu Widya Artana, I Gusti Bagus Satria Wisesa, I Komang Setiawan, Ni Luh Putu Mita Pramestya Utami, Ni Nyoman Kerti Yasa, dan Made Jatra. Pengaruh Store Atmosphere, Display Product, dan Price Discount...

\section{Pengaruh Display Product terhadap Impulse Buying}

Berdasarkan penelitian yang dilakukan oleh Yugiantoro (2014), Mithiah dkk (2018) menyatakan bahwa penataan produk dapat berpengaruh secara positif signifikan terhadap Impulse Buying. yang mana hasil penelitian tersebut juga sejalan dengan penelitian yang dilakukan oleh Winawan dan Yasa (2014), yang juga menyatakan hal yang sama bahwa penataan produk berpengaruh positif signifikan terhadap impukse buying.

Berdasarkan hasil penelitian sebelumnya, maka hipotesis dalam penelitian ini adalah sebagai berikut:

\section{H2: Display Product mempunyai pengaruh positif dan signifikan terhadap} Impulse Buying.

\section{Pengaruh Price Discount terhadap Impulse Buying}

Pada penelitian yang dilakukan oleh Gumilang dan Nurcahya (2016), Melina dan Kadafi (2017) menyatakan bahwa Price Discount mempunyai pengaruh positif dan signifikan terhadap Impulse Buying. penelitian ini juga didukung oleh penelitian yang dilakukan oleh Setyaningrum dkk. (2016), Suhiryanto dkk. (2018) yang juga menyatakan bahwa Price Discount mempunyai pengaruh positif signifikan terhadap Impulse Buying.

Berdasarkan hasil penelitian sebelumnya, maka hipotesis dalam penelitian ini adalah sebagai berikut:

H3: Price Discount mempunyai pengaruh positif dan signifikan terhadap Impulse Buying. 


\section{METODE PENELITIAN}

Penelitian ini dilaksanakan di seluruh gerai indomaret yang berada di wilayah kota Denpasar, yang mana kota Denpasar dipilih sebagai lokasi penelitian karena kota Denpasar adalah salah satu kota terpadat di Indonesia dengan jumlah gerai indomaret yang cukup banyak, sehingga kemungkinan penduduk kota Denpasar untuk melakukan pembelian implusif cukup tinggi. Adapun objek dalam penelitian ini adalah pengaruh Store Atmosphere, Display Product, dan Price Discount terhadap Impulse Buying.

Penelitian ini menggunakan jenis data yang dikelompokkan menurut sifatnya yaitu, data kualitatif dan kuantitatif. Data kualitatif dalam penelitian ini adalah pendapat dari para responden terhadap pernyataan kuesioner mengenai pengaruh atmosfer toko, Display Product, dan Price Discount terhadap Impulse Buying (studi kasus pada indomaret di kota Denpasar). Data kuantitatif dalam penelitian ini adalah data mengenai jawaban kuesioner dari anggota sample yang diukur dengan skala Likert.

Sumber data yang digunakan dalam penelitian ini adalah sumber primer dan sekunder. Sumber primer dalam penelitian ini adalah para responden yang memberikan tanggapan dalam kuesioner mengenai variabel-variabel dalam penelitian. Sumber sekunder dalam penelitian ini adalah pihak lain yang mempublikasikan data yang dikutip terkait topik penelitian ini seperti jurnal, buku dan lain-lain.

Variable-variabel penelitian dalam penelitian ini antara lain: 1) Variabel bebas adalah variabel yang menjadi penyebab timbulnya atau berubahnya variabel 
Putu Widya Artana, I Gusti Bagus Satria Wisesa, I Komang Setiawan, Ni Luh Putu Mita Pramestya Utami, Ni Nyoman Kerti Yasa, dan Made Jatra. Pengaruh Store Atmosphere, Display Product, dan Price Discount...

terikat. Variabel bebas dalam penelitian ini adalah atmosfer toko (X1), Display Product (X2), Price Discount (X3). 2) Variabel terikat adalah variabel yang dipengaruhi atau variabel yang menjadi akibat atas keberadaan variabel bebas. Dalam penelitian ini yang menjadi variabel terikat adala Impulse Buying (Y).

Penelitian ini menggunakan populasi seluruh masyarakat yang sudah pernah membeli produk di indomaret yang berada di wilayah kota Denpasar. Ukuran sebuah sampel yang baik adalah 5-10 kali jumlah variabel atau indicator dalam penelitian. Penelitian ini menggunakan 12 indikator sehingga estimasi responden dalam penelitian ini adalah sebanyak 60 sampai 120 orang. Penelitian ini menggunakan teknik pengambilan sampel nonprobability sampling, yaitu purposive sampling, dimana peneliti memilih anggota populasi yang dinilai paling tepat sesuai dengan kriteria tertentu. Adapaun kriteria responden dalam penelitian ini adalah sebagai berikut: 1) Pendidikan terkahir SMA sederajat. Pertimbangan ini digunakan karena peneliti menganggap bahwa orang-orang dengan Pendidikan minimal SMA sederjat dapat memahami isi dari kuesioner dengan baik. 2) Bertempat ringgal di Kota Denpasar. 3)Pernah membeli produk di gerai indomaret yang berada di wilayah Kota Denpasar. Dalam penelitian ini data dikumpulkan melalui instrument penelitian berupa kuesioner. Metode pengumpulan data berupa penyebaran kuesioner yang secara langsung disebarkan oleh peneliti. Penelitian ini menggunakan 60 responden. Teknik analisis yang digunakan adalah analisis deskriptif dan analisis regresi berganda. 


\section{HASIL DAN PEMBAHASAN}

Karekateristik responden dalam penelitian ini dapat dilihat dari variabel demografi yaitu, jenis kelamin, usia pekerjaan, usia, dan tingkat Pendidikan yang dapat dilihat sebagai berikut.
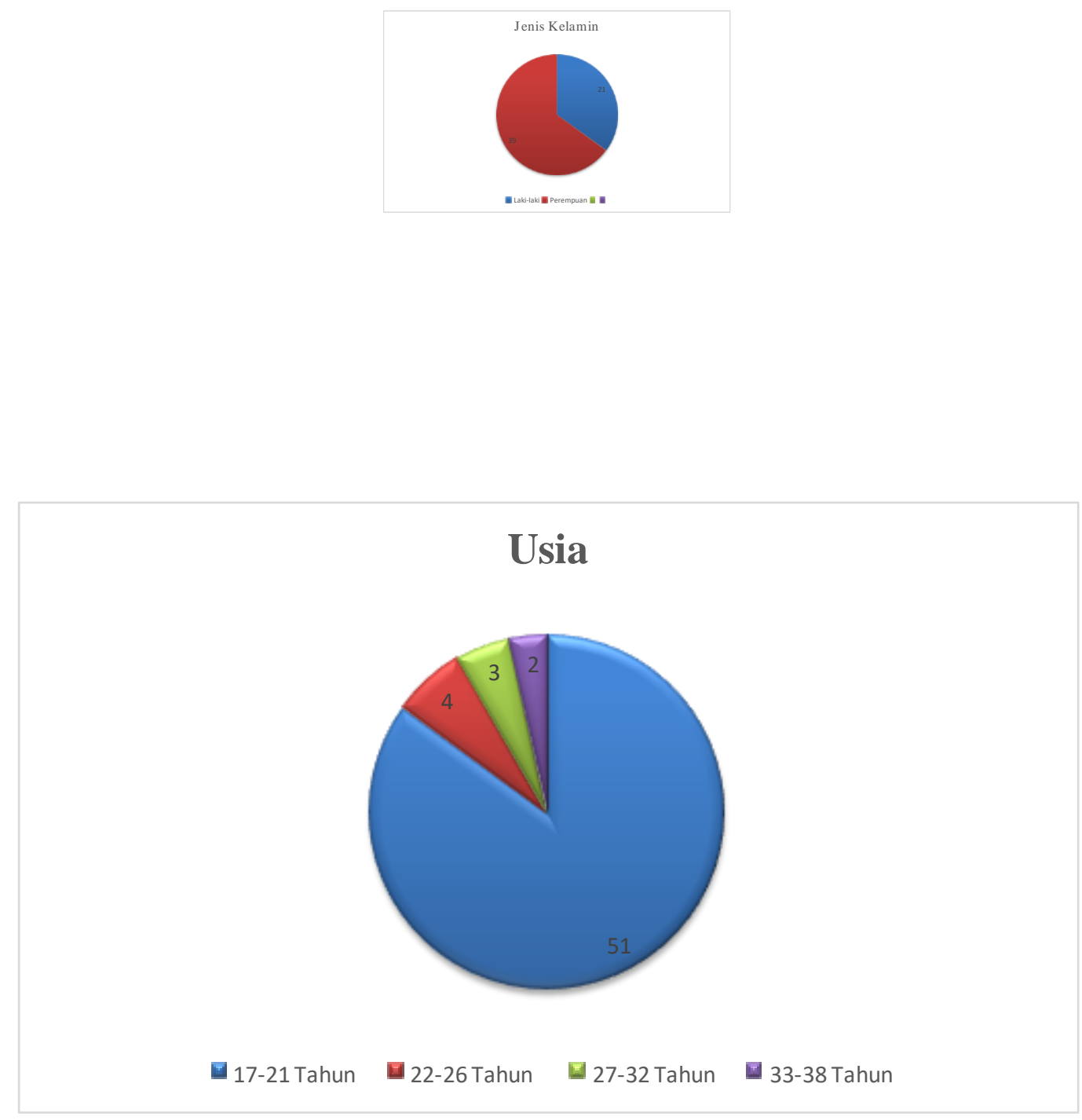
Putu Widya Artana, I Gusti Bagus Satria Wisesa, I Komang Setiawan, Ni Luh Putu Mita Pramestya Utami, Ni Nyoman Kerti Yasa, dan Made Jatra. Pengaruh Store Atmosphere, Display Product, dan Price Discount...

\section{Pendidikan Terakhir}

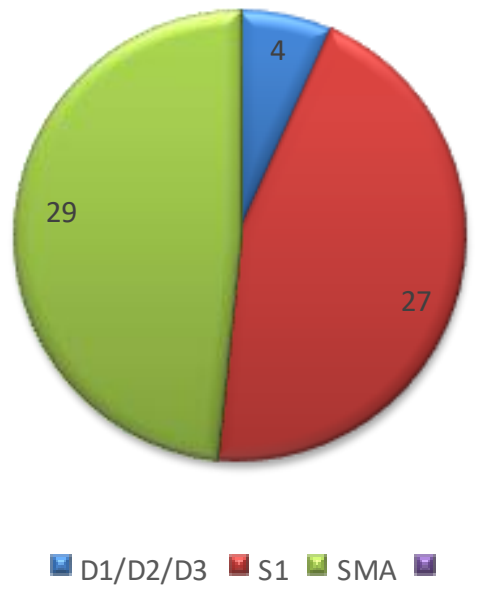

\section{Pekerjaan}

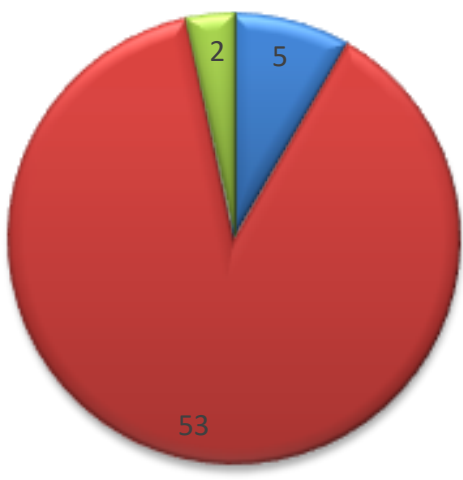

Pegawai Swasta

Pelajar/Mahasiswa

Wiraswasta

Berdasarkan uji validitas pada penelitian ini, mengahsilkan seluruh koefisien korelasi dari indikator variabel yang diuji memiliki nilai lebih besar dari $0,30(\mathrm{r}>0,3)$. Hal tersebut dapat diihat pada Tabel 1 
Tabel 1

Hasil Uji Validitas

\begin{tabular}{|c|c|c|c|c|}
\hline No & Variabel & $\begin{array}{c}\text { Item } \\
\text { Pernyataan }\end{array}$ & $\begin{array}{c}\text { Korelasi Item } \\
\text { Total }\end{array}$ & Keterangan \\
\hline 1 & Store Atmosphere & X1.1 & 0.832 & Valid \\
& & X1.2 & 0.896 & Valid \\
& & X1.3 & 0.791 & Valid \\
\hline 2 & Display Product & X2.1 & 0.785 & Valid \\
& & X2.2 & 0.900 & Valid \\
& & X2.3 & 0.758 & Valid \\
& & X3.1 & 0.949 & Valid \\
3 & Price Discount & X3.2 & 0.917 & Valid \\
& & X3.3 & 0.898 & Valid \\
& & Y1.1 & 0.826 & Valid \\
\hline 4 & Impulse Buying & Y1.2 & 0.652 & Valid \\
& & Y1.3 & 0.795 & Valid \\
& & & & \\
\hline
\end{tabular}

Berdasarkan uji reliabilitas nilai masing-masing Cronbach's Alpha setiap instrumen lebih besar dari 0,6 (Cronbach's Alpha > 0,6) yang menunjukkan semua instrumen reliabel, yang berarti bisa dipergunakan melakukan penelitian, yang dapat dilihat pada Tabel 2

Tabel 2

Hasil Uji Reliabilitas

\begin{tabular}{|l|c|c|}
\hline \multicolumn{1}{|c|}{ Variabel } & Cronbach's Alpha & Keterangan \\
\hline Store Atmosphere $(X 1)$ & 0.746 & Reliabel \\
Display Product $(X 2)$ & 0.908 & Reliabel \\
Price Discount $(X 3)$ & 0.894 & Reliabel \\
Impulse Buying $(Y)$ & 0.627 & Reliabel \\
& & \\
\hline
\end{tabular}


Putu Widya Artana, I Gusti Bagus Satria Wisesa, I Komang Setiawan, Ni Luh Putu Mita Pramestya Utami, Ni Nyoman Kerti Yasa, dan Made Jatra. Pengaruh Store Atmosphere, Display Product, dan Price Discount...

Analisis ini mengacu pada hasil pengaruh Store Atmosphere, Display Product, dan Price Discount yang diperoleh dari penyebaran kuesioner dengan distribusi tersebar. Uji regresi linear berganda menggunakan program SPSS 17.0 dengan persamaan regresi linear berganda sebagai berikut:

$\begin{array}{llll}\mathrm{Y} & =0,000+0,084\left(\mathrm{X}_{1}\right)+0,316\left(\mathrm{X}_{2}\right)+0,404\left(\mathrm{X}_{3}\right) \\ \mathrm{SE} & =0.164 & 0.187 & 0.158 \\ \text { Thitung } & =-0.724 & 2.142 & 3.101 \\ \text { Sig } & =0.472 & 0.037 & 0.003 \\ \mathrm{R}^{2} & =0.507 & & \\ \text { Fhitung } \quad=19.163 & \\ \text { Sig } \quad=0.000 \\ \text { Keterangan: } \\ \mathrm{Y}=\text { Impulse Buying } \\ \text { X1 = Store Atmosphere } \\ \text { X2 = Display Product } \\ \text { X3 = Price Discount }\end{array}$

Persamaan regresi linear berganda menunjukkan arah masing-masing variabel bebas terhadap variabel terikatnya. Nilai $R^{2}$ penelitian ini adalah 0,507 , yang berarti bahwa sebesar 50,7 persen Store Atmosphere, Display Product dan Price Discount mempengaruhi keputusan Impulse Buying di Indomaret dikota Denpasar, sedangkan sisanya sebesar 49.3 persen dipengaruhi oleh faktor lainnya. Berdasarkan uji normalitas pada penelitian ini memperoleh hasil bahwa variabel-variabel yang terdapat pada penelitian ini memenuhi syarat normalitas. Uji multikoleniaritas mendapatkan hasil pengujian tolerance $>0,10$, perhitungan VIF menunjukan bahwa variable-variabel bebas mempunyai nilai $\mathrm{VIF}<10$ seperti yang dapat dilihat pada Tabel 3 
Tabel 3

Hasil Uji Multikolinearitas (Tolerance dan VIF)

\begin{tabular}{|c|c|c|}
\hline Variabel & Tolerance & VIF \\
\hline Store Atmosphere (X1) & 0.650 & 1.539 \\
Display Product (X2) & 0.404 & 2.472 \\
Price Discount (X3) & 0.519 & 1.926 \\
& & \\
\hline
\end{tabular}

Berdasarkan uji heteroskedastisitas memperoleh hasil bahwa tidak ada gejala heteroskedastisitas. Pengujian yang dilakukan menunjukkan hasil bahwa signifikansinya lebih dari $\alpha=0,05$ terhadap absolut residual (Abs_Res) secara parsial, yang dapat dilihat pada Tabel 4

Tabel 4

Hasil Uji Heteroskedasitas (Metode Glejser)

\begin{tabular}{|c|c|c|}
\hline Variabel & T & Signifikansi \\
\hline Store Atmosphere (X1) & 1.573 & 0.121 \\
Display Product (X2) & 0.196 & 0.846 \\
Price Discount (X3) & -1.248 & 0.217 \\
& & \\
\hline
\end{tabular}

Berdasarkan uji simultan atau uji $\mathrm{F}$ yang dilakukan pada penelitian ini mengungkapkan bahwa Store Atmosphere, Display Product dan Price Discount, secara simultan mempunyai pengaruh yang signifikan terhadap Impulse Buying. Berdasarkan hasil penelitian terlihat bahwa nilai signifikansi $F=0,000$ yang kurang dari 0,05.

Tabel 5

Hasil Uji Hipotesis (uji t)

\begin{tabular}{|c|c|c|c|}
\hline Variabel & $\begin{array}{c}\text { Standardized } \\
\text { Coefficients Beta }\end{array}$ & T & Sign. \\
\hline Store Atmosphere (X1) & 0.084 & 0.724 & 0.472 \\
\hline Display Product (X2) & 0.316 & 2.142 & 0.037 \\
\hline Price Discount (X3) & 0.404 & 3.101 & 0.003 \\
\hline
\end{tabular}


Putu Widya Artana, I Gusti Bagus Satria Wisesa, I Komang Setiawan, Ni Luh Putu Mita Pramestya Utami, Ni Nyoman Kerti Yasa, dan Made Jatra. Pengaruh Store Atmosphere, Display Product, dan Price Discount...

\section{Pengaruh Store Atmosphere terhadap Impulse Buying}

Berdasarkan uji parsial atau uji t pada Tabel 5 dapat dilihat bahwa nilai signifikansi uji t pada Store Atmosphere menunjukan nilai 0.472, dikarenakan 0.472>0.05 maka $\mathrm{H}_{0}$ diterima. Berdasarkan hasil ini dapat dikatakan bahwa Store Atmosphere tidak mempunyai pengaruh yang signifikan terhadap Impulse Buying pada konsumen indomaret yang berada di kota Denpasar.

\section{Pengaruh Display Product terhadap Impulse Buying}

Berdasarkan uji hipotesis atau uji t seperti yang terdapat pada Tabel 5, dapat dilihat bahwa nilai signifikansi t untuk variabel Display Product adalah sebesar 0.037, oleh karena $0.037<0.05$ maka $\mathrm{H}_{0}$ ditolak. Berdasarkan hasil tersebut, dapat dikatakan bahwa Display Product mempunyai pengaruh positif dan signifikan terhadap Impulse Buying pada konsumen indomaret yang berada di kota Denpasar. Penelitian ini memperoleh hasil yang sama dengan penelitian yang dilakukan oleh Winawan dan Yasa (2014) yang juga menyatakan bahwa Display Product mempunyai pengaruh positif dan signifikan terhadap Impulse Buying.

\section{Pengaruh Price Discount Terhadap Impulse Buying}

Berdasarkan hasil uji hipotesis atau uji t seperti yang dapat dilihat pada Tabel 5, memeperoleh hasil nilai signifikansi t pada variabel Price Discount adalah sebesar 0.03 , karena nilai $0.03<0.05$ maka $\mathrm{H}_{0}$ ditolak. Berdasarkan hasil tersebut, dapat dikatakan bahwa Price Discount mempunayi pengaruh positif dan signifikan terhadap Impulse Buying pada konsumen indomaret di kota Denpasar. Hasil penelitian ini juga sejalan dengan hasil penelitian yang dilakukan oleh 
Gumilang dan Nurcahya (2016) yang juga menyatakan bahwa Price Discount mempunyai pengaruh positif dan signifikan terhadap Impulse Buying.

\section{IMPLIKASI PENELITIAN}

Berdasarkan penelitian ini ada beberapa implikasi temuan dari peneliti dengan kebijakan yang akan dilakukan, serta berbagai strategi pemasaran yang dapat dilakukan oleh pemasar indomaret di kota Denpasar. Pada variabel atmosfer toko walaupun tidak berpengaruh signifikan, pemasar juga harus tetap memperhatikan atmosfer toko ini terutama pada pencahayaan toko yang mana indikator pencahayaan toko ini mempunyai nilai rata-rata yang paling tinggi jika dibandingkan dengan indikator-indikator yang lain pada variabel atmosfer toko ini

Indikator interior display atau pemajangan produk di dalam gerai menjadi indikator dengan nilai rata-rata tertinggi dibandingkan dengan indikator lainnya yang ada pada variabel Display Product, oleh karena itu pemasar juga sebaiknya memperhatikan hal ini, karena dengan interior display yang baik konsumen juga akan merasa tertarik pada produk-produk yang ditawarkan pada indomaret khsusnya di kota Denpasar. Pada variabel Price Discount indikator frekuensi diskon menjadi indikator yang mempunyai nilai rata-rata yang paking tinggi dibandingkan dengan indikator lainnya yang terdapat pada variabel Price Discount, oelh karena itu pemasar dalam hal ini melakukan diskon dengan frekuensi yang tinggi sehingga dapat menarik konsumen untuk melakkan pembelian implusif. 
Putu Widya Artana, I Gusti Bagus Satria Wisesa, I Komang Setiawan, Ni Luh Putu Mita Pramestya Utami, Ni Nyoman Kerti Yasa, dan Made Jatra. Pengaruh Store Atmosphere, Display Product, dan Price Discount...

\section{SIMPULAN DAN PENELITIAN MASA DEPAN}

Berdasarkan hasil penelitian dan pembahasan yang telah dilakukan, maka dapat disimpulkan bahwa Store Atmosphere tidak mempunyai pengaruh yang signifikan terhadap Impulse Buying pada konsumen indomaret di kota Denpasar, Display Product mempunyai pengaruh positif dan signifikan terhadap Impulse Buying pada konsumen indomaret di kota Denpasar, Price Discount mempunyai pengaruhpositif dan signifikan terhadap Impulse Buying terhadap konsumen indomaret di kota Denpasar.

Berdasarkan penelitian yang telah dilakukan ini, terdapat saran bagi penelitian yang akan dilakukan pada masa yang akan datang. Penelitian ini mengambil cakupan yang sempit yang terbatas pada indomaret di kota Denpasar saja, oleh karena itu peneliti menganggap akan lebih baik jika penelitian yang akan datang dilakukan dengan mencakup wilayah yang lebih luas seperti pulau bali. Responden kuesioner dalam penelitian ini sebagina besar diisi oleh kalangan pelajar saja yang berusia 17-21 tahun, peneliti menganggap akan lebih baik penelitian yang akan datang dilakukan dengan responden dengan karakter demografi yang lebih bervariasi.

\section{REFRENSI}

Alma, B. 2014. Manajemen Pemasaran Dan Pemasaran Jasa. Bandung: CV Alfabeta.

Amiri, Farhad, Jasour, jalal, shir pour, Mohsen, alized. 2012. Evaluation of effective fashionism involment factors effects on Impulse Buying of customer and condition of interrelation between these factors. Journal of Basic And Applied Scientific Research, 2 (2), pp: 1-9 
Arvinisa Herawati., Ari Pradhanawati., Dan Reni Shinta Dewi. 2013. Pengaruh Bauran Pemasaran Ritel Terhadap Loyalitas Pelanggan Melalui Kepuasan Pelanggan Pada Konsumen Alfamart Di Kecamatan Tembalang Semarang. Diponegoro. Journal Of Social And Politic, 2 (2),Pp:1-9

Bayley Geoff and Nancarrow Clive. 2007. Impulse ourchasing: a qualitative exploration of the phenomenon, qualitative market research: aninternational. Qualitative Market Research: An International Journal. 1 (2). Pp: 99-114.

Chen, Haipeng, Marmorstein, Howard, Michael Tsiros, Dan Akshay R. Rao. 2012. Where More Is Less: The Impact Of Base Value Neglect On Consumer Preferences For Bonus Packs Over Price Discounts.

Choudhary, Shweta. 2014. Study of Impulse Buying Behavior of Consumers. International Journal Of Advance Research In Computer Science And Management Studies. Vol.2

Christina Whidya Utami. 2010. Manajemen Ritel: Strategi Dan Implementasi Operasional Bisnis Ritel Modern Di Indonesia. Edisi ke 2. Jakarta: salemba empat.

Darmayasa, Ni Made Intan Agustina Ariani Dan Sukaatmadja, I Putu Gde. 2017. Analisis Pengaruh Store Atmosphere Dan Sales Promotion Terhadap Emotional Shopping Dan Impulse Buying Behavior. E-Jurnal Manajemen Unud, 6 (11), pp. 6061-6089.

Dewi, Kadek Trisna Dan Giantari, I Gusti Ayu Ketut. 2015. Peran Emosi Positif Dalam Memediasi Store Atmosphere Terhadap Pembelian Impulsif. EJurnal Manajemen Unud, 4 (12). Pp. 4419-4448

Dharma, Putu Gde Krisnandadifa .Dan Kusumadewi, Ni Made Wulandari. 2018. Peran Emosi Memediasi Pengaruh Store Atmosphere Terhadap Perilaku Pembelian Di Karakter Kopi. E-Jurnal Manajemen Unud, 7 (12), pp. 6815 6841.

Gumilang, Wayan Aris Dan Nurcahya, I Ketut. 2016. Pengaruh Price Discount Dan Store Atmosphere Terhadap Emotional Shopping Dan Impulse Buying. E-Jurnal Manajemen Unud, 15 (3), pp. 1859-1888.

https://www.indomaret.co.id/korporat/seputar-indomaret/peduli-danberbagi/2014/01/16/gerai-indomaret/ (diakses 20 Maret 2019)

https://www.tiendeo.co.id/toko/denpasar/indomaret (diakses 20 Maret 2019) 
Putu Widya Artana, I Gusti Bagus Satria Wisesa, I Komang Setiawan, Ni Luh Putu Mita Pramestya Utami, Ni Nyoman Kerti Yasa, dan Made Jatra. Pengaruh Store Atmosphere, Display Product, dan Price Discount...

Hadjali, Hamid Reza., Meysam Salimi., \& Masomeh Sadat Ardestanis. 2012. Exploring Main Factors Affecting on Impulse Buying Behaviours. Journal of American Science, 8 (1), pp: 245 - 251

Hussain, Riaz And Mazhar Ali. 2015. Effect Of Store Atmosphere On Consumer Purchese Intention . International Journal Of Marketing Studies. 7 (2), pp. :35-43.

Kacen, Jacqueline J. Dan Julie Anne Lee. 2002. Influence Of Culture On Consumer Implusive Buying Behavior. Journal Of Consumer Psychology, 12 (2), 163-176.

Khorrami, Maryam Sarikhani dan Esfidani, Mohammad Rahim. 2015. The Effect of Situational Factors on Impulse Buying and Compulsive Buying: Clothing. $2(8)$.

Kotler. 2005. Manajemen Pemasaran (I), Jilid 1 Dan 2:Pt. Indeks Kelompok Gramedia Jakarta

Kurniawan, Denny Dan Kunto, Yohanes Sanding. 2013. Pengaruh Promosi Dan Store Atmosphere Terhadap Impulse Buying Dengan Shopping Emotion Sebagai Variabel Intervening Studi Kasus Di Matahari Department Store Cabang Supermall Surabay. Jurnal Manajemen Pemasaran Petra. 1 (2), Pp: $1-8$.

Ma`Aruf, H. 2006. Pemasaran Ritel. Jakarta. PT. Gramedia Pustakan Utama.

Maymand, Mohammad Mahmoudi., \& Mostofa Ahmadinejad. 2011. Impulse Buying: the role of store environmental stimulation and situational factors (an empirical investigation). African journal of business management, 5 (34), pp: 13057-13065.

Melina Dan Kadafi, M Amin. 2017. Pengaruh Price Discount Dan In-Store Display Terhadap Impulse Buying. Forum Ekonomi, 19 (2),

Muthiah Ismah. Dian A.S Parawansa, Abdul Razak Munir. 2018. Pengaruh Visual Merchandising, Display Product, Dan Store Atmosphere Terhadap Perilaku Impulse Buying (Studi Kasus: Konsumen Matahari Department Store Di Kota Makassar). Hassanudin Journal Of Applied Business And Entrepreneurship. Hjabe . 1(2). pp: 23-40.

Nouman Ahad, Nazish Tanveer,Tanzila Ali, Zoya Khanum. 2015. Impulse Buying Behavior and its Influential Factors. Scholars Journal of Economics, Business and Management. 2 (7A):703-706. 
Pemayun, Tjokorda Istri Dwi Pradnyawati Dan Ekawati, Ni Wayan. 2016. Pengaruh Promosi, Atmosfer Gerai, Dan Merchandise Terhadap Pembelian Impulsif Pada Hardy's Mall Gatsu Denpasar. E-Jurnal Manajemen Unud, 5 (7), pp. $4132-416$

Pontoh Marcella Engelin, Sileyljeova Moniharapon Dan Ferdy Roring. 2017. Pengaruh Display Produk Dan Store Atmosphere Terhadap Impulse Buying Pada Konsumen Matahari Departemen Store Mega Mall Manado. Jurnal EMBA. 5 (2), ppl. 1823-1833.

Rahmadana, Maya Sari. Pengaruh Display Produk Dan Suasana Toko Terhadap Pembelian Impulsif Di Minimarket Eramart Cabang Lembuswana Samarinda. 2016. Ejournal Ilmu Administrasi Bisnis. 4 (3): 683-697.

Sari D Dan Ikhwan Faizal. 2018. Pengaruh Price Discount, Bomus Pack, Dan InStore Display Terhadap Keputusan Impulse Buying Pada Giant Ekstra Banjar. Junal Sains Manajemen Dan Kewirausahaan. 2 (1). Pp. 51-60.

Sarma, Dr Sasmitha. 2014. A Study Of Retail Display And Impulse Buying Behavior, Journal Of Marketing And Consumer Research - An Open Access International Journal. 4 Pp: 51-55.

Setiawati, A. A Diah Dan Sukawati, Tjok. Gde Raka. 2017. Pengaruh Merchandise Dan Atmosfer Gerai Terhadap Nilai Hedonik Dan Perilaku Pembelian Impulsif Di Lippo Mall Kuta. E-Jurnal Manajemen Unud, 6 (9), pp. 5205-523.

Setyaningrum, Febe Yustina, Zainul Arifin, Dan Edy Yulianto. 2016. Pengaruh Hedonic Motives Terhadap Shopping Lifestyle Dan Impulse Buying (Survei Pada Konsumen Superindo Supermarket Yang Melakukan Impulse Buying). Jurnal Administrasi Bisnis. 7 (1).

Soliha, Euis. 2008. Analisis Industry Ritel Di Indonesia. Jurnal Bisnis Dan Ekonomi (JBE), 15 (2), Pp:128-142.

Suhriyanto, Rois Arifin, Dan Afi Rachmat Slame. Pengaruh Shopping Lifestyle, Discount Dan Fashion Involvement Terhadap Impulse Buying Pada Mahasiswa Pengunjung Matos. Jurnal Ilmiah Riset Manajemen. 7 (7).

Temaja, I Km. Wisnu Bayu, Rahanatha, Gede Bayu Dan Yasa,Ni Nyoman Kerti. 2015. Pengaruh Fashion Involvement, Atmosfer Toko Dan Promosi Penjualan Terhadap Impulse Buying Pada Matahari Department Store Di Kota Denpasar. E-Jurnal Manajemen Unud, 4 (6), pp. 1466-1482.

Tjiptono, Fandy \& Diana 2016. Pemasaran Esensi Dan Aplikasi. Yogyakarta. C.V Andi Offset. 
Putu Widya Artana, I Gusti Bagus Satria Wisesa, I Komang Setiawan, Ni Luh Putu Mita Pramestya Utami, Ni Nyoman Kerti Yasa, dan Made Jatra. Pengaruh Store Atmosphere, Display Product, dan Price Discount...

Wahyudi, Septian. Pengaruh Price Discount Terhadap Impulse Buying. 2017. Jurnal Valuta, 3 (2)..

Winawan, Boy Dan Yasa, Ni Nyoman Kerti. 2014. Pengaruh Penataan Produk, Jenis Kelamin, Dan Daftar Belanja Terhadap Keputusan Pembelian Tidak Terencana. E-Jurnal Manajemen, 3 (7). 